\title{
Comparison Study on Anode Materials of Lithium-Ion Battery Applied in Tibet
}

\author{
Guangzhou Zhang1, Heming Deng1*, Buqiong Xiao², Tianyu Hou², Yue Song2, Nima Shida², \\ Hang $\mathbf{Q i}^{3}$, Anat Deepatana ${ }^{3}$, Shun Tang ${ }^{*}$ \\ ${ }^{1}$ State Grid Electric Power Research Institute, Wuhan, China \\ ${ }^{2}$ Electric Power Research Institute of Xizang Electric Power Co. Ltd., Lhasa, China \\ ${ }^{3}$ Faculty of Engineering, Burapha University, Chon Buri, Thailand \\ ${ }^{4}$ State Key Laboratory of Advanced Electromagnetic Engineering and Technology, School of Electrical and Electronic Engineering, \\ Huazhong University of Science and Technology, Wuhan, China \\ Email: *dengheming@sgepri.sgcc.com.cn, *shun.tang@hotmail.com
}

How to cite this paper: Zhang, G.Z., Deng, H.M., Xiao, B.Q., Hou, T.Y., Song, Y., Shida, N., Qi, H., Deepatana, A. and Tang, S. (2019) Comparison Study on Anode Materials of Lithium-Ion Battery Applied in Tibet. Journal of Power and Energy Engineering, 7, 42-50.

https://doi.org/10.4236/jpee.2019.712003

Received: November 8, 2019

Accepted: December 7, 2019

Published: December 10, 2019

Copyright $\odot 2019$ by author(s) and Scientific Research Publishing Inc. This work is licensed under the Creative Commons Attribution International License (CC BY 4.0).

http://creativecommons.org/licenses/by/4.0/

\begin{abstract}
Lithium-ion battery is facing the capacity fade in cold area. It reports in this paper to improve the temperature-tolerance using the novel materials in the battery design. Mesophase carbon microspheres (MG11) composed of $2 \mathrm{H}+3 \mathrm{R}$ graphite phase with more uniform size were used as anode material and a new binder (WRA268) was used. The tests results show that at $0^{\circ} \mathrm{C}$, MG11 using conventional binder (styrene butadiene rubber, SBR) attains $66 \%$ of reversible capacity retention rate, and synthetic graphite (FSN-1) using WRA268 as binder attains $76.9 \%$ of reversible capacity retention rate, but it attains $34 \%$ for the FSN-1 using SBR as the binder. These results show that MG11WRA268 is promising materials using for battery in cold areas such as Tibet.
\end{abstract}

\section{Keywords}

Lithium-Ion Battery, Anode, Cold Area, Energy Storage

\section{Introduction}

In the last few decades, including nickel metal-hydride batterys [1] [2], lead-acid cells and lithium-ion batteries were used as energy storage battery [3]. In comparison, lithium-ion batteries are relatively mature for commercial applications in many spheres of our life. Their advantages such as high energy density have various unmatchable applications [4]. Thus, lithium-ion battery is one of the best options for energy storage equipments in electrical power systems. A typical lithium-ion battery consists of an anode (such as graphite [5]), a separator [6] These authors contributed equally to this work. 
(e.g. PE, PP) and a cathode (such as lithium cobalt oxides [7], lithium manganese oxide [8]. The process of charging and discharging of lithium-ions battery corresponds to phenomena on a carbon negative electrode that lithium ion intercalation and deintercalation and on positive electrode that lithium ion deintercalation and intercalation [9].

Recent years, our interest in researching on lithium-ion batteries has focused on the extraordinary conditions such as cold areas. But the poor efficiency at low temperature has become an obstruction for development of power sources in cold area [10]. When the temperature falls to $0^{\circ} \mathrm{C}$ or below, both capacity and energy of the Li-ion batteries are reduced substantially [11]. Therefore, it is urgent to find suitable lithium ion battery materials with high capacity and stability at low temperature. The performance of Li-ion batteries at low temperatures is inherently related to characteristic of material components, such as the particle size, electrical resistance, cell parameters. Hereto, MG11 was used as anode material and was tested in different temperatures in our experiment compared with FSN-1. Meanwhile, different binders were used to compare, proving the importance of binder selection.

\section{Materials and Methods}

LB-303, 1.0 $\mathrm{M} \mathrm{LiPF}_{6}$ solution in a mixture of ethyene catrbonate (EC), diethyl carbonate (DEC) and dimethyl carbonate DMC $\left(\mathrm{W}_{\mathrm{EC}}: \mathrm{W}_{\mathrm{DEC}}: \mathrm{W}_{\mathrm{DMC}}=1: 1: 1\right)$ was used as an electrolyte. Mesophase carbon microspheres (MG11) from China Steel Chemical Corp and artificial graphite (FSN-1) from Shanshan Corporation were used as anode materials. New high-performance binder (WRA268) from Graymont was used as binder compare with SBR, CMC was also used to work with WRA268 or SBR.

Button cells with a diameter of $20 \mathrm{~mm}$ and thickness of $25 \mathrm{~mm}$ were assembled as a testing half-cell in a glove-box filled with argon. Before assembling for the electrochemical measurements, all the electrode materials were dried under vacuum drying oven at $80^{\circ} \mathrm{C}$ for $16 \mathrm{~h}$.

\section{Results and Discussion}

To investigate the composition of anode materials, the X-ray diffraction (XRD) pattern of MG11 and FSN-1 was carried out and displayed in Figure 1. Most of the diffraction peek can match the PDF\# 41-1487, proving exist of Graphite-2H in which MG11 and FSN-1 are identical. Magnification image of XRD from 42 degrees (2 $\theta)$ to 47 degrees show two weak peaks in MG11 that ascribe to crystal face (101) and (012) of Graphite-3R, demonstrate not only does it contain Graphite-2H in MG11 but a small amount of Graphite-3R.

Morphology, structure of the FSN-1 and MG11 were characterized by SEM (Figure 2). The particle size was analyzed by laser particle analyzer (Figure 3 ). The SEM image of the FSN-1 sample indicates that it has a bulk composition with many lumps that are not uniform, while MG11 has the typical spherical 


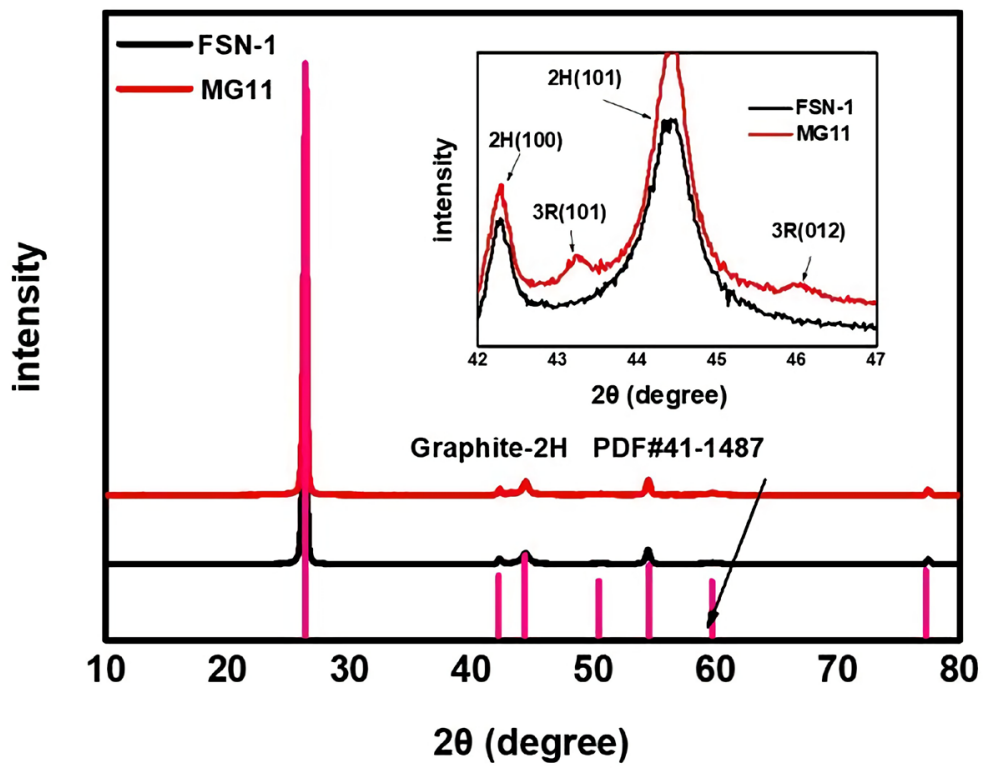

Figure 1. The XRD pattern of MG11 and FSN-1; insets: Magnification image of XRD with $2 \theta$ from 42 degrees to 47 degrees.

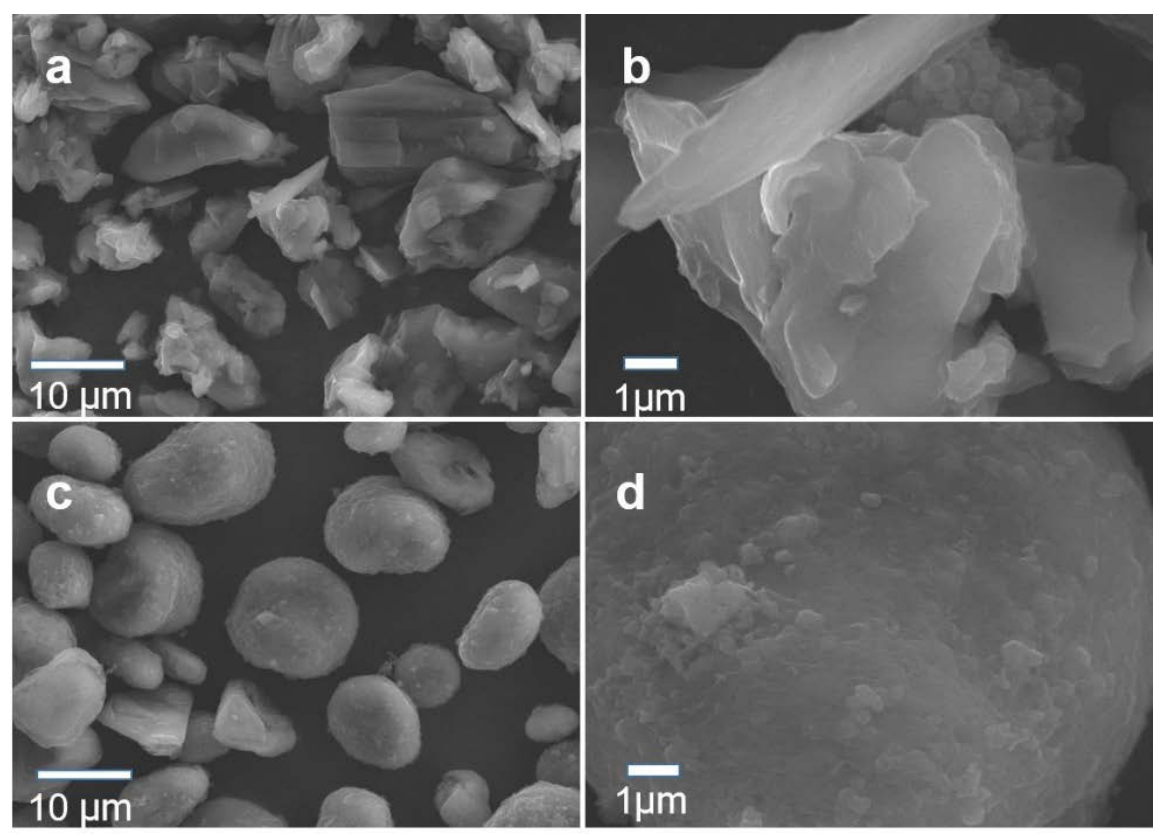

Figure 2. SEM images of (a), (b) FSN-1 and (c), (d) MG11 with different magnification.

morphology with more uniform size. This has also been confirmed by laser particle analyzer. As it is shown in Figure 3, most particles in FSN-1 present a diameter of $7.4 \mu \mathrm{m}$ to $29.0 \mu \mathrm{m}$ and in MG11 narrowed it down from $7.71 \mu \mathrm{m}$ to $15.5 \mu \mathrm{m}$. Specific surface area was detected by Brunauer-Emmett-Teller test $\left(\mathrm{N}_{2}-\mathrm{BET}\right)$ (Figure 4), which reveals the BET surface area of FSN-1 and MG11 $\left(0.96 \mathrm{~m}^{2} / \mathrm{g}\right.$ and $2.14 \mathrm{~m}^{2} / \mathrm{g}$ respectively). All above suggest that the MG11 has uniform particle size distribution, composed of spherical particles, with a large specific surface area that may promote the mass transfer. 

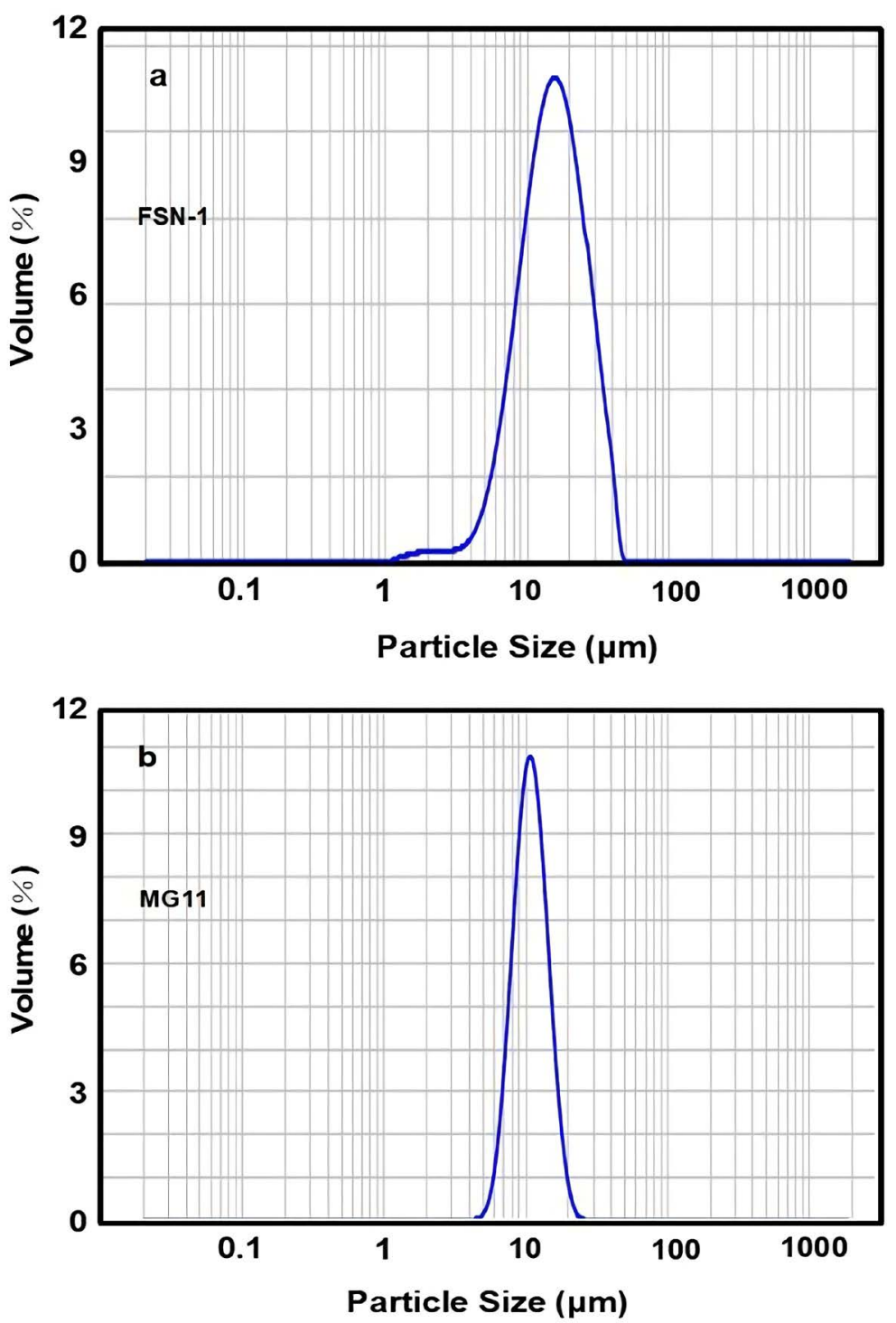

Figure 3. Particle size distribution analysis diagram of (a) FSN-1 and (b) MG11.

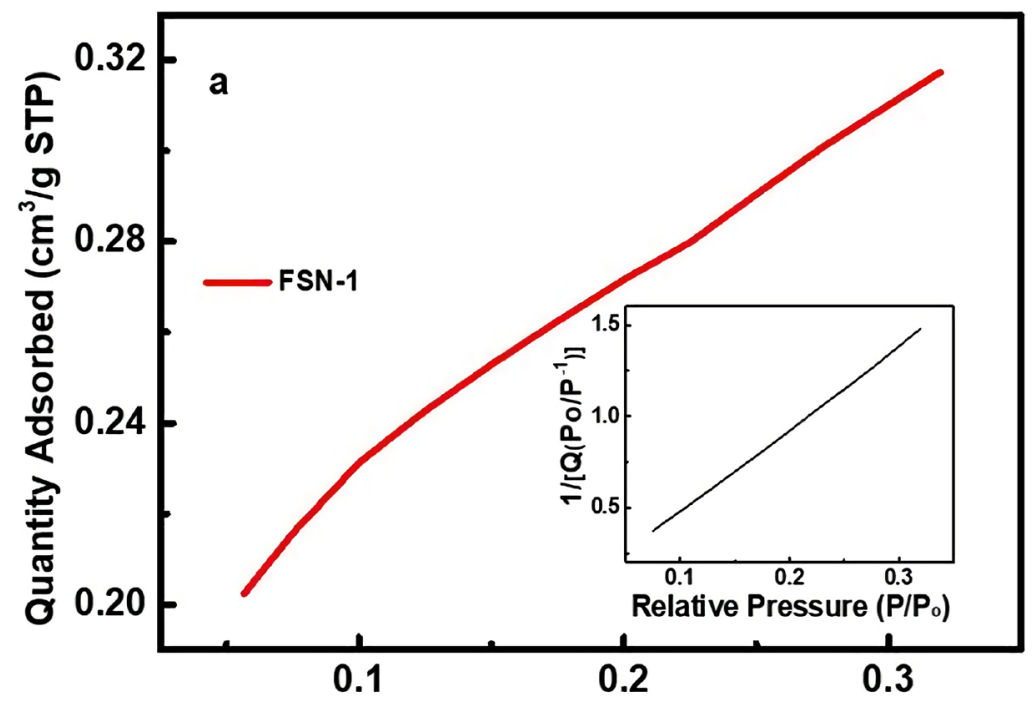




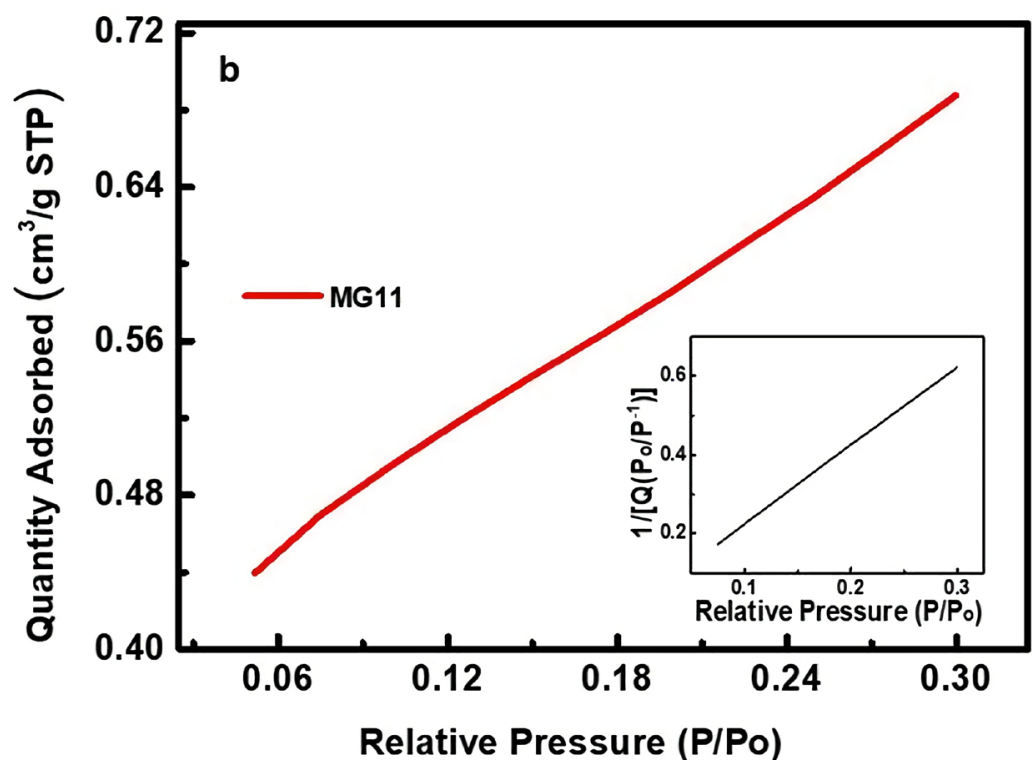

Figure 4. $\mathrm{N}_{2}$-BET graph of (a) FSN-1 and (b) MG11.

The performance of different anode materials and different bind is evaluated by a standard electrochemical method based on anode/Li haft cell where FSN-1/ MG11 and lithium foil serve as positive and negative electrode, respectively. All potential denoted here is versus $\mathrm{Li}^{-} \mathrm{Li}^{+}$reference.

Charge and discharge curves of FSN-1 and MG11 were shown in Figure 5(a) and Figure 5(b). It can be seen that a lithium storage capacity of $336 \mathrm{mAh} / \mathrm{g}$ and $370 \mathrm{mAh} / \mathrm{g}$ were delivered by FSN-1 and MG11 during the initial discharge process, and a relatively low reversible capacity of 325 and $358 \mathrm{mAh} / \mathrm{g}$ was achieved in the following cycle respectively, leading to an initial coulombic efficiency of around $96.72 \%$ and $96.49 \%$. The irreversible capacity loss of both can ascribe to SEI and decomposition of electrolyte, which is commonplace to most anode materials [12].

When it was focused on the binder, FSN-1 using WRA268 binder reached a stable lithium storage capacity of $337 \mathrm{mAh} / \mathrm{g}$. The charge and discharge curves were shown in Figure 6. From all above it can see that using MG11 as anode materials or WRA268 as binder can increase capacity of cells at room temperature, but the effect of WRA268 is limited.

As is shown in Figure 7, the capacity of FSN-1 at $0^{\circ} \mathrm{C}$ was reduced to $34 \%$ of that at $25^{\circ} \mathrm{C}$, which is much lower than the performance of MG11: at $0^{\circ} \mathrm{C}$, its capacity only reduced to $66 \%$ of $25^{\circ} \mathrm{C}$. The relatively superior properties of MG11 at low temperatures may associated with its composition of $2 \mathrm{H}+3 \mathrm{R}$ phase or uniform particle size distribution and shapes of spherical particles, with a large specific surface area that may benefit to the mass transfer. As for FSN-1 using WRA268 binder, it maintains $76.9 \%$ of reversible storage capacity that even exceeds MG11 using SBR binder (Figure 8).

In order to further understand the influencing factors of materials MG11, WRA268 in capacities at low temperatures was studied. Nyquist plots of these 

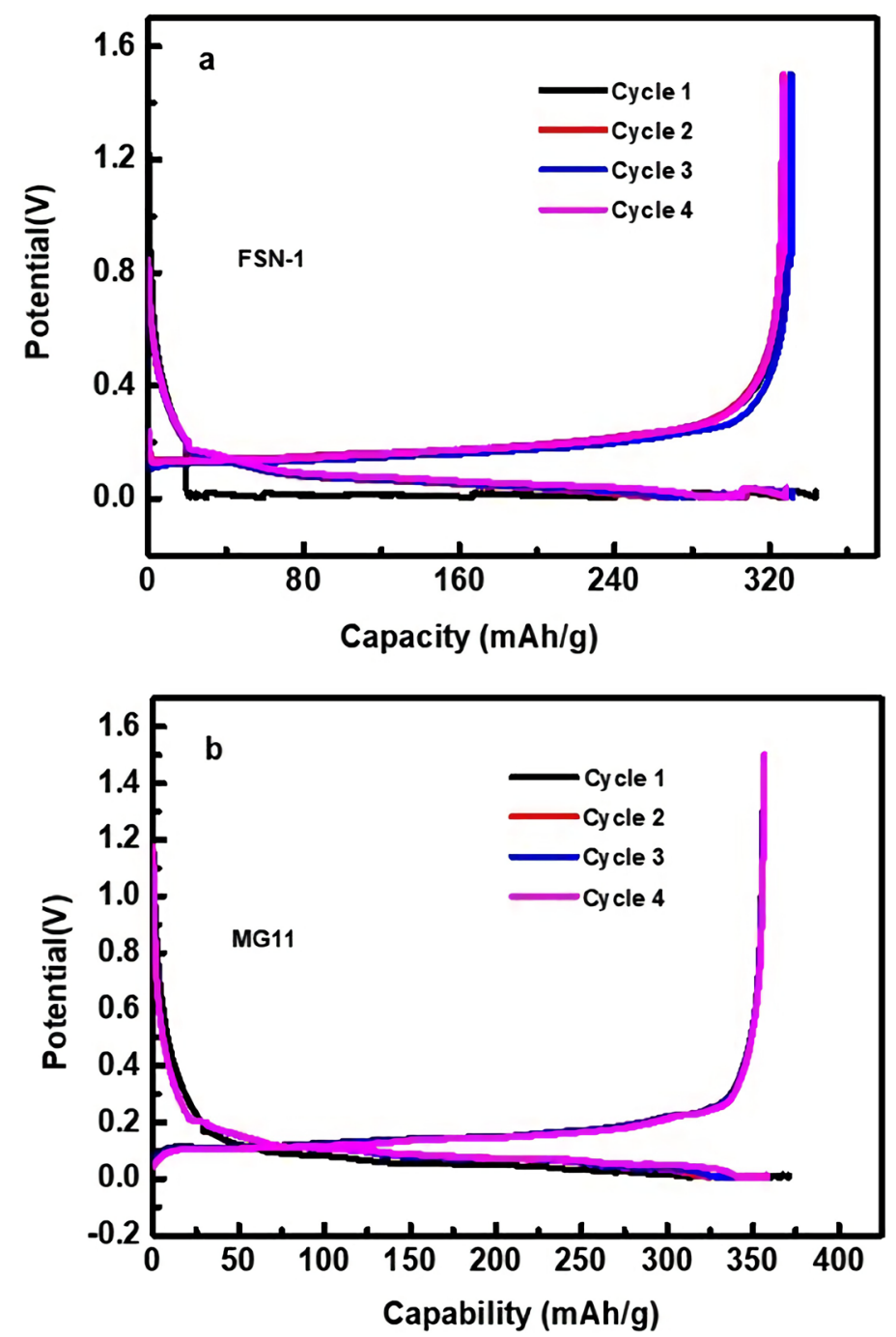

Figure 5. Charge and discharge curves of (a) FSN-1 and (b) MG11.

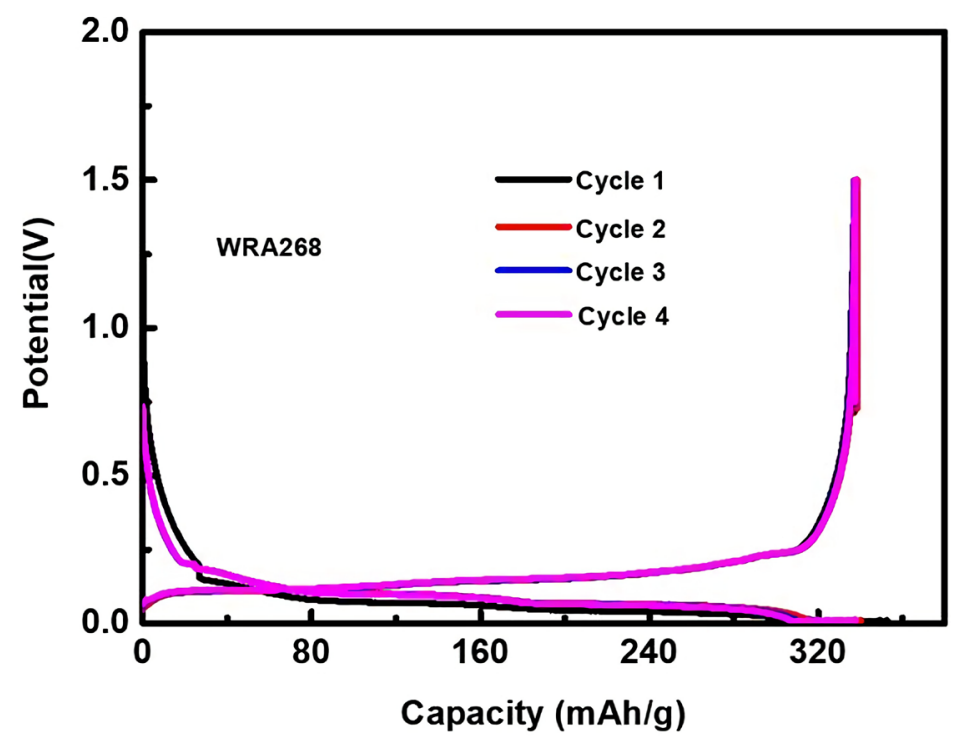

Figure 6. Charge and discharge curves of FSN-1 used WRA268 binder. 


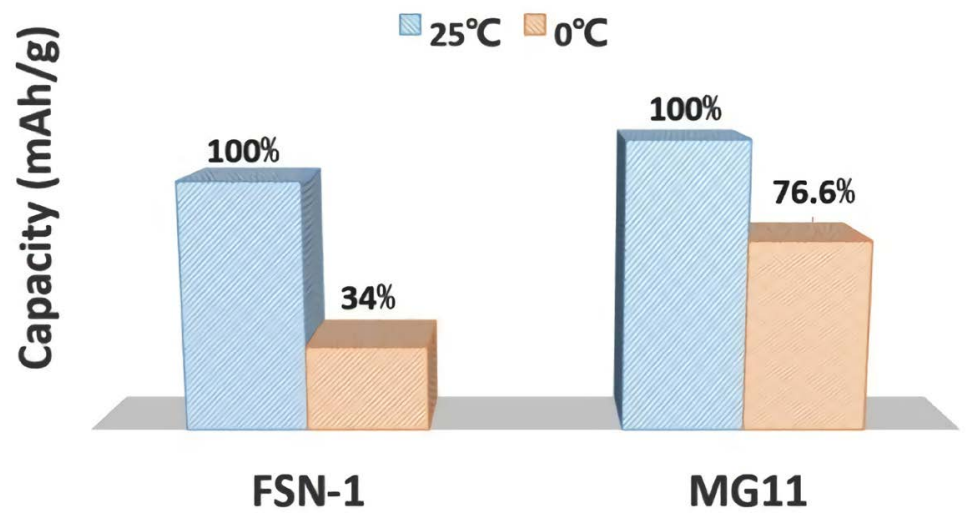

Figure 7. The capacities of FSN-1 and MG11 using SBR as binder in different temperatures.

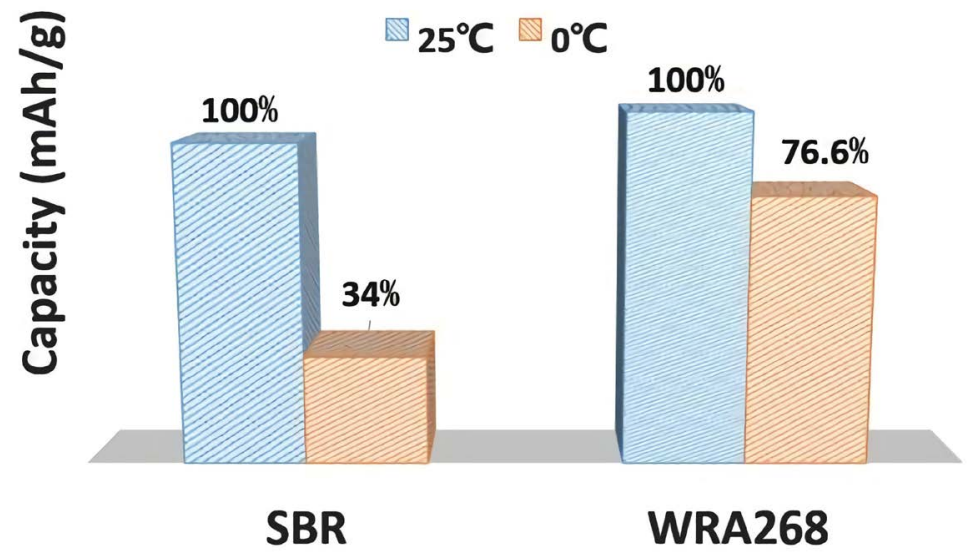

Figure 8. The capacities of FSN-1 using SBR and FSN-1 using WRA268 as binder in different temperatures.

cells at $25^{\circ} \mathrm{C}$ and $0^{\circ} \mathrm{C}$ are plotted in Figure 9. The impedance curve of them are composed of two semicircles and a straight sloping line which represent resistance $\left(\mathrm{R}_{\text {sei }}\right)$ and capacitance $\left(\mathrm{C}_{\text {sei }}\right)$ of SEI film, double layer capacitance $(\mathrm{Cdl})$ and Rct, warburg impedance (W) related to a combination of the diffusional effects of lithium ion at the interface between the active material particles and electrolyte. The $\mathrm{R}_{\mathrm{ct}}$ of FSN-1 Cell using SBR or WRA268 as binder is bigger than MG11 using $\mathrm{SBR}$ at $25^{\circ} \mathrm{C}$ (Figure 9), which demonstrate its better Kinetics process at room temperature of MG11 compare with FSN-1. And all of them are increase when the temperature drops to $0^{\circ} \mathrm{C}$, but the increments of FSN-1 Cell that use WRA268 binder is relatively small compare to FSN-1 that use normal binder. That means the WRA268 can slow the decline in kinetics electrochemical reaction of cells.

\section{Conclusion}

Mesophase carbon microspheres MG11 were used as the negative electrode material compare to FSN-1; WRA268 was used as binder compare to SBR. The relatively superior properties of MG11 at low temperatures may associate with 

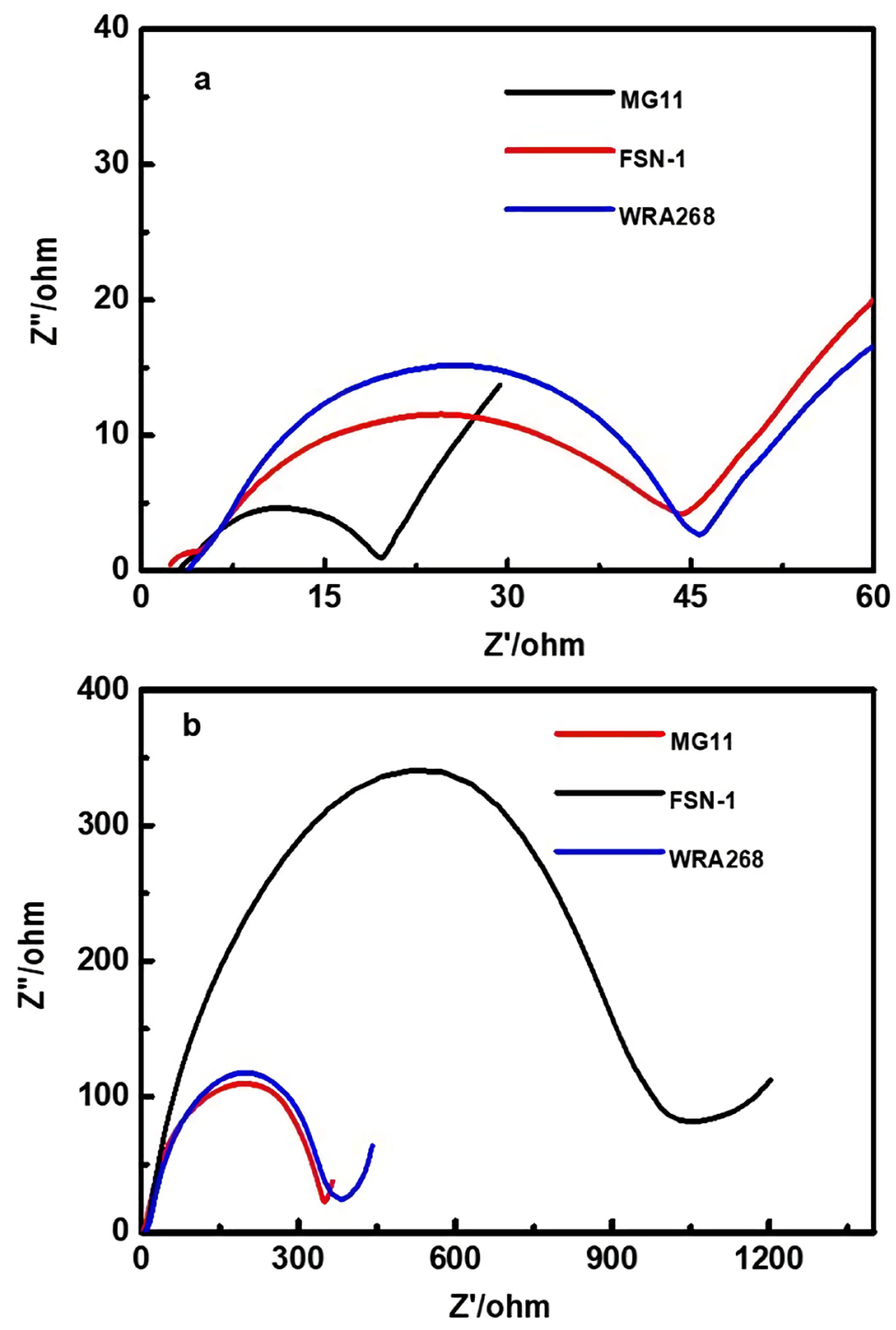

Figure 9. Nyquist plots of FSN-1 and MG11 and FSN-1 using WRA268 binder cell at (a) $25^{\circ} \mathrm{C}$ and (b) $0^{\circ} \mathrm{C}$.

its composition of $2 \mathrm{H}+3 \mathrm{R}$ phase or uniform particle size distribution and shapes of spherical particles. Character with a large specific surface area is beneficial to the mass transfer. Moreover, FSN-1 cell that uses WRA268 binder is superior compared to FSN-1 that uses conventional binder. It is because the WRA268 can slow the decline in kinetics electrochemical reaction of cells in cold area, proving the importance of binder selection.

\section{Conflicts of Interest}

The authors declare no conflicts of interest regarding the publication of this paper.

\section{References}

[1] Scrosati, B., Hassoun, J. and Sun, Y.K. (2011) Lithium-Ion Batteries. A Look into 
the Future. Energy \& Environmental Science, 4, 3287-3295.

https://doi.org/10.1039/c1ee01388b

[2] Liu, Y.F., Pan, H., Gao, M.X., et al. (2011) Advanced Hydrogen Storage Alloys for $\mathrm{Ni}$ /MH Rechargeable Batteries. Journal of Materials Chemistry, 21, 4743-4755. https://doi.org/10.1039/C0JM01921F

[3] Goodenough, J.B. and Park, K.-S. (2013) The Li-Ion Rechargeable Battery: A Perspective. Journal of the American Chemical Society, 135, 1167-1176. https://doi.org/10.1021/ja3091438

[4] Nitta, N., Wu, F.X., Lee, J.T., et al. (2014) Li Ion Battery Materials: Present and Future. Materials Today, 18, 252-264. https://doi.org/10.1016/j.mattod.2014.10.040

[5] Liu, Y.Y., Wang, Y.M., Yakobson, B.I., et al. (2014) Assessing Carbon-Based Anodes for Lithium-Ion Batteries: A Universal Description of Charge-Transfer Binding. Physical Review Letters, 113, Article ID: 028304. https://doi.org/10.1103/PhysRevLett.113.028304

[6] Venugopal, G., Moore, J., Howard, J., et al. (1999) Characterization of Microporous Separators for Lithium-Ion Batteries. Journal of Power Sources, 77, 34-41. https://doi.org/10.1016/S0378-7753(98)00168-2

[7] Ozaw, K. (1994) Lithium-Ion Rechargeable Batteries with $\mathrm{LiCoO}_{2}$ and Carbon Electrodes: The $\mathrm{LiCoO}_{2} / \mathrm{C}$ System. Solid State Ionics, 69, 212-221. https://doi.org/10.1016/0167-2738(94)90411-1

[8] Guyomard, D. and Tarascon, J.M. (1992) Li Metal-Free Rechargeable $\mathrm{LiMn}_{2} \mathrm{O}_{4} /$ Carbon Cells: Their Understanding and Optimization. Journal of the Electrochemical Society, 139, 937-948. https://doi.org/10.1149/1.2069372

[9] Ji, L.W., Lin, Z., Alcoutlabi, M., et al. (2011) Recent Developments in Nanostructured Anode Materials for Rechargeable Lithium-Ion Batteries. Energy \& Environmental Science, 4, 2682-2699. https://doi.org/10.1039/c0ee00699h

[10] Rodrigues, M.T.F., Babu, G., Gullapalli, H., et al. (2017) A Materials Perspective on Li-Ion Batteries at Extreme Temperatures. Nature Energy, 2, Article No. 17108. https://doi.org/10.1038/nenergy.2017.108

[11] Zhang, S.S., Xu, K. and Jow, T.R. (2003) The Low Temperature Performance of Li-Ion Batteries. Journal of Power Sources, 115, 137-140. https://doi.org/10.1016/S0378-7753(02)00618-3

[12] He, C., Wu, S., Zhao, N.Q., et al. (2013) Carbon-Encapsulated $\mathrm{Fe}_{3} \mathrm{O}_{4}$ Nanoparticles as a High-Rate Lithium Ion Battery Anode Material. ACS Nano, 7, 4459-4469. https://doi.org/10.1021/nn401059h 